\title{
Intraocular pressure changes after peribulbar injections with and without ocular compression
}

\author{
Richard Bowman, Christopher Liu, Nicholas Sarkies
}

\begin{abstract}
Aim-Two prospective studies were carried out in order to investigate (1) the rise in intraocular pressure (IOP) following peribulbar anaesthesia with a fixed volume of anaesthetic agent administered by a single surgeon, and (2) the efficacy of ocular compression with the Honan balloon for lowering IOP. Glaucomatous eyes were excluded from both studies.

Methods-In study group 1,36 eyes of 36 patients undergoing cataract and/or implant surgery each received peribulbar injections consisting of $5 \mathrm{ml}$ of anaesthetic from an inferotemporal site through the conjunctiva and a further $5 \mathrm{ml}$ from a medial injection through the caruncle. IOP values were measured immediately before and after the injections and then after a variable period of external ocular compression. In study group 2,20 eyes of 20 patients undergoing cataract surgery received peribulbar injections of local anaesthetic as above. IOP values were measured immediately before and after the injections and after 20 minutes without ocular compression. After a further 20 minute period with ocular compression the IOP was again measured.
\end{abstract}

Results-In study group 1, the mean immediate rise in IOP induced by the injections was $11.44(95 \%$ confidence interval 8.97-13.90) $\mathrm{mm}$ Hg. The mean change in IOP after ocular compression was an overall fall of $2.42(0 \cdot 49-4 \cdot 34) \mathrm{mm}$ $\mathrm{Hg}$ from the pre-injection value. In study group 2, the mean injection induced rise in IOP was 9.45 (6.90-12.00) $\mathrm{mm} \mathrm{Hg}$. The mean fall in IOP during the first 20 minutes without ocular compression was $2.85(1 \cdot 20-4 \cdot 50) \mathrm{mm}$ Hg. During the second 20 minutes with ocular compression the mean fall in intraocular pressure was $11.05(8 \cdot 14-14 \cdot 96) \mathrm{mm} \mathrm{Hg}$.

Conclusions-There is a large and individually variable rise in IOP following peribulbar anaesthesia. Ocular compression with the Honan balloon is effective in reversing this rise even when the initial rise is large.

(Br f Ophthalmol 1996; 80: 394-397)

Peribulbar anaesthesia is a widely used local anaesthetic technique for eye surgery in the UK. The usual volume of anaesthetic agent used varies between 6 and $10 \mathrm{ml}$ and since the average orbital volume is only $30 \mathrm{ml}$ there is an associated rise in intraorbital and intraocular pressure (IOP). The magnitude of this immediate post-injection rise is variable $\mathrm{e}^{1-3}$ and the volume of anaesthetic used may have an effect. ${ }^{24}$

Because of the desirability of low IOP (and low vitreous pressure) during intraocular surgery, some form of ocular compression is often applied for a variable period of time either before but usually after administration of peribulbar anaesthesia. Ocular compression has been shown to be effective in lowering IOP in normal eyes in the absence of intraorbital injection $^{5}$ as well as in eyes which have received peribulbar injections. ${ }^{6}$ A recently published study questions the necessity of ocular compression. ${ }^{7}$

The aim of this study was, firstly, to identify the extent and the variability in IOP rise immediately after peribulbar injection and, secondly, to investigate the importance of ocular compression in facilitating the subsequent IOP fall. Previous studies have been hampered by including differing techniques and volumes of injectate within the same study, measuring IOP values at inappropriate intervals and in some cases not having excluded patients with glaucoma or separated them out before data analysis. We have addressed these issues in the present study by having a single surgeon use the same technique and volume of injectate in all cases studied.

\section{Patients and methods}

Study group 1 consisted of 36 consecutive patients undergoing peribulbar anaesthesia for cataract and/or implant surgery. IOP measurements were made immediately before $(\mathrm{A})$ and immediately after administration of the anaesthetic (B) with the Perkins handheld applanation tonometer. Each patient received $5 \mathrm{ml}$ of anaesthetic from an inferotemporal injection through the conjunctiva and a further $5 \mathrm{ml}$ from a medial injection through the caruncle. The anaesthetic solution consisted of $5 \mathrm{ml}$ of lignocaine $2 \%$ with 1 in 200000 adrenaline and $5 \mathrm{ml}$ of $0.5 \%$ bupivacaine. A Honan's ocular compression balloon was then applied to the eye and inflated to a pressure of $30 \mathrm{~mm} \mathrm{Hg}$ for a variable duration range (D) immediately after which the IOP was again measured (C).

Study group 2 consisted of 20 consecutive patients undergoing peribulbar anaesthesia for cataract surgery. The anaesthetic technique and anaesthetic agents used were identical to those for study 1 . IOP values were measured immediately before (A) and immediately after administration of the anaesthetic (B). After a period of 20 minutes (without ocular compression) the IOP was measured $\left(\mathrm{C}^{\prime}\right)$ before applying a Honan's balloon as above for a further 20 
Table 1 Study group 1: mean values, 95\% confidence limits (CL), and range of compression duration (minutes) and IOP measurements/changes before and after peribulbar injections and ocular compression $(\mathrm{mm} \mathrm{Hg})$

\begin{tabular}{|c|c|c|c|c|c|c|}
\hline \multicolumn{2}{|l|}{ Variable } & \multirow{2}{*}{$\begin{array}{r}\text { Mean } \\
14 \cdot 14 \\
25 \cdot 58 \\
11 \cdot 72 \\
11 \cdot 44 \\
-13 \cdot 86 \\
-2 \cdot 42 \\
26 \cdot 31\end{array}$} & \multirow{2}{*}{$\begin{array}{l}95 \% C L \\
12 \cdot 66,15 \cdot 61 \\
22 \cdot 30,28 \cdot 87 \\
9 \cdot 99,13 \cdot 46 \\
8 \cdot 97,13 \cdot 90 \\
-16 \cdot 70,-11 \cdot 02 \\
-4 \cdot 34,-0 \cdot 49 \\
22 \cdot 24,30 \cdot 37\end{array}$} & \multirow{2}{*}{$\begin{array}{r}\text { Min } \\
5 \\
12 \\
4 \\
1 \\
-40 \\
-18 \\
7\end{array}$} & \multirow{2}{*}{$\begin{array}{c}M a x \\
28 \\
50 \\
25 \\
31 \\
-3 \\
7 \\
60\end{array}$} & \multirow[b]{2}{*}{$\begin{array}{l}n \\
36 \\
36 \\
36 \\
36 \\
36 \\
36 \\
36\end{array}$} \\
\hline $\begin{array}{l}\text { (A) } \\
\text { (B) } \\
(\mathrm{C}) \\
(\mathrm{B}-\mathrm{A}) \\
(\mathrm{B}-\mathrm{C}) \\
(\mathrm{C}-\mathrm{A}) \\
\text { (D) }\end{array}$ & $\begin{array}{l}\text { Pre-injection IOP } \\
\text { Post-injection IOP } \\
\text { Post-compression IOP } \\
\text { Change in IOP following injections } \\
\text { Change in IOP during compression } \\
\text { Overall change in IOP } \\
\text { Duration of compression (minutes) }\end{array}$ & & & & & \\
\hline
\end{tabular}

minutes. The IOP was again measured on removal of the balloon ( 40 minutes after the injections had been given) (C).

In both studies, patients, with glaucoma or anterior chamber angle abnormalities were excluded. All injections and IOP measurements were performed by a single surgeon (RJCB). Informed consent (written) was obtained from each patient and local ethics committee approval had been obtained.

For both study groups the mean values and 95\% confidence intervals were calculated for the IOP measurements and changes through the various stages of the procedure. The Student's two tailed paired $t$ test was used to test the statistical significance of the changes in intraocular pressure. For study group 1 linear regression analysis was used to assess the possible significance of duration of ocular compression (D) on the magnitude of the fall in IOP during compression $(\mathrm{C}-\mathrm{B})$.

\section{Results}

The mean values (95\% confidence intervals) and ranges for the IOP measurements and changes during the various stages of the procedure as well as for the duration of oculopression (D) (study group 1 only) are shown in Tables 1 and 2 according to study group.

\section{STUDY GROUP 1}

The mean change in IOP induced by the injections (B-A) was an increase of $11.44 \mathrm{~mm} \mathrm{Hg}$ $(t=9.46, \quad \mathrm{p}<0.0005)$. The distribution of immediate rise in IOP following injections $(B-A)$ is shown in Figure 1. The mean change in IOP during oculopression $(\mathrm{C}-\mathrm{B})$ was a drop of $13.86 \mathrm{~mm} \mathrm{Hg}(t=-9.91, \mathrm{p}<0.0005)$ and the mean overall change in IOP after injection and oculopression $(\mathrm{C}-\mathrm{A})$ was a drop of $2.42 \mathrm{~mm} \mathrm{Hg}(t=-2.54, \mathrm{p}=0.016)$. The duration of oculopression (D) had a very low and statistically insignificant correlation value of $r=0.07(\mathrm{p}=0.68)$ with the fall in IOP during oculopression (C-B).
STUDY 2

The mean change in IOP induced by the injections was $9.45 \mathrm{~mm} \mathrm{Hg}(t=7 \cdot 76, \mathrm{p}<0.0005)$. The distribution of immediate rise in IOP following injections (B-A) is shown in Figure 2. The mean change in IOP during the first 20 minutes without oculopression was a drop of $2.85 \mathrm{~mm} \mathrm{Hg}(t=-3.63, \mathrm{p}=0.002)$ and during the second 20 minutes with oculopression was a drop of $11.55 \mathrm{~mm} \mathrm{Hg}(t=-7 \cdot 10$, $\mathrm{p}<0.0005)$. The drop in IOP which occurred during oculopression was significantly greater than the drop which occurred during the first 20 minutes without it $(t=4.59, \mathrm{p}<0.0005)$.

\section{Discussion}

Like others, 347 we have demonstrated that there is a large and individually variable rise in IOP following peribulbar anaesthesia. This variability is present despite our uniformity of technique, using the same sites, speed, and volume of injection given by a single surgeon. Stevens $e t a l^{2}$ found a greater rise in IOP using peribulbar anaesthesia as compared with retrobulbar or sub-Tenon's anaesthesia and they attributed this to the greater volume used in the peribulbar technique (average immediate IOP rise of $4.9 \mathrm{~mm} \mathrm{Hg}$ with an average injection volume of $6.4 \mathrm{ml}$ ). The peribulbar injections, however, were given by different surgeons using different volumes and techniques. They suggested that the use of larger volumes might produce larger pressure rises and our results would support this, with higher average IOP rises at $11.44 \mathrm{~mm} \mathrm{Hg}$ in study 1 and $9.45 \mathrm{~mm} \mathrm{Hg}$ in study 2 using a volume of $10 \mathrm{ml}$. A French study also demonstrated that $16 \mathrm{ml}$ of injectate produced a larger rise in IOP compared with $10 \mathrm{ml}^{4}$ While we would agree that the volume of injectate is an important factor in determining the rise in IOP, given our results, other factors such as variation in orbital volume and tightness of the orbital septum must play a role. ${ }^{3}$

Pressure of theatre time and organisation during study 1 precluded the measurement of IOP after a fixed time period of oculopression. While this prevents direct comparison of results of studies 1 and 2, the variable duration of oculopression in study 1 allows assessment of the significance of duration of oculopression. Constable and Porter ${ }^{5}$ studied the time course of IOP decrease with oculopression in normal eyes (without injection of anaesthetic agents), measuring IOP at 10 minute intervals for 50 minutes. They found a non-linear relation with time with the greatest drop occurring in the first 10 minutes. In our study repeated before and after injection and delayed ocular compression

\begin{tabular}{|c|c|c|c|c|c|c|}
\hline Variable & & Mean & $95 \% C L$ & Min & $\operatorname{Max}$ & $n$ \\
\hline $\begin{array}{l}\text { (A) } \\
(\mathbf{B}) \\
\left(\mathbf{C}^{\prime}\right) \\
(\mathbf{C}) \\
(\mathbf{B}-\mathbf{A}) \\
\left(\mathbf{C}^{\prime}-\mathbf{B}\right) \\
\left(\mathbf{C}-\mathbf{C}^{\prime}\right) \\
(\mathbf{C}-\mathbf{A})\end{array}$ & $\begin{array}{l}\text { Pre-injection IOP } \\
\text { Post-injection IOP } \\
\text { IOP after } 20 \text { minutes (no compression) } \\
\text { IOP after } 40 \text { minutes ( } 20 \text { minutes compression) } \\
\text { Change in IOP following injection } \\
\text { Change in IOP during } 20 \text { minutes (no compression) } \\
\text { Change in IOP during } 2 \text { nd } 20 \text { minutes (compression) } \\
\text { Overall change in IOP }\end{array}$ & $\begin{array}{r}15 \cdot 50 \\
24 \cdot 95 \\
22 \cdot 10 \\
10 \cdot 55 \\
9 \cdot 45 \\
-2 \cdot 85 \\
-11 \cdot 55 \\
-4 \cdot 95\end{array}$ & $\begin{array}{r}13 \cdot 46,17 \cdot 54 \\
21 \cdot 55,28 \cdot 35 \\
18 \cdot 98,25 \cdot 22 \\
8 \cdot 59,12 \cdot 51 \\
6 \cdot 90,12 \cdot 00 \\
-4 \cdot 50,-1 \cdot 20 \\
-14 \cdot 96,-8 \cdot 14 \\
-7 \cdot 37,-2 \cdot 53\end{array}$ & $\begin{array}{r}10 \\
16 \\
14 \\
3 \\
0 \\
-11 \\
-31 \\
-21\end{array}$ & $\begin{array}{r}26 \\
45 \\
38 \\
22 \\
22 \\
6 \\
-2 \\
3\end{array}$ & $\begin{array}{l}20 \\
20 \\
20 \\
20 \\
20 \\
20 \\
20 \\
20\end{array}$ \\
\hline
\end{tabular}




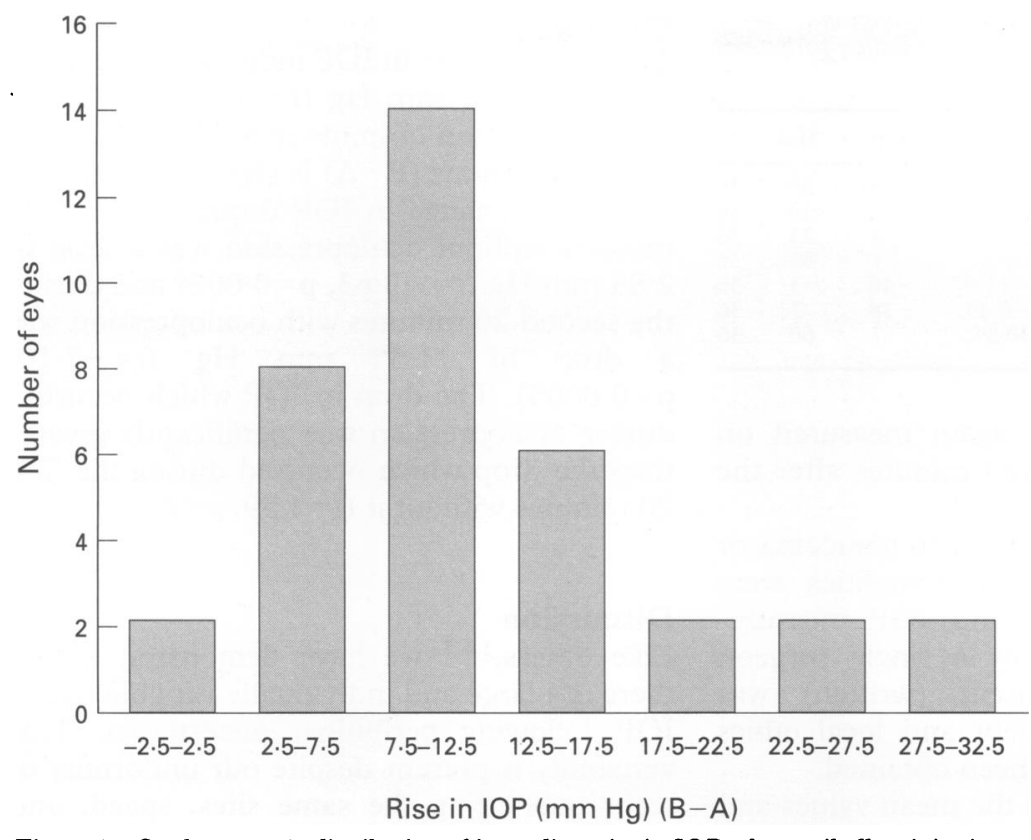

Figure 1 Study group 1: distribution of immediate rise in IOP after peribulbar injections $(B-A)$.

IOP measurements were not made during oculopression for three reasons. Firstly, it was felt that repeated removal and reapplication of the oculopression might have affected the pattern of IOP fall. Secondly, several applanations were already being made and further measurements may have put the cornea at risk. Thirdly, repeated measurement may itself affect IOP.

Despite the lack of IOP versus time curves for individual patients the variable duration of oculopression undergone by each patient allowed the use of linear regression analysis to evaluate the importance of duration of oculopression as a factor influencing the magnitude of fall in IOP. There was only a small and statistically insignificant positive correlation between IOP drop and duration. This seems to be consistent with previous findings that most of the IOP drop occurs during the first 10 minutes. ${ }^{56}$ In our study the mean duration of

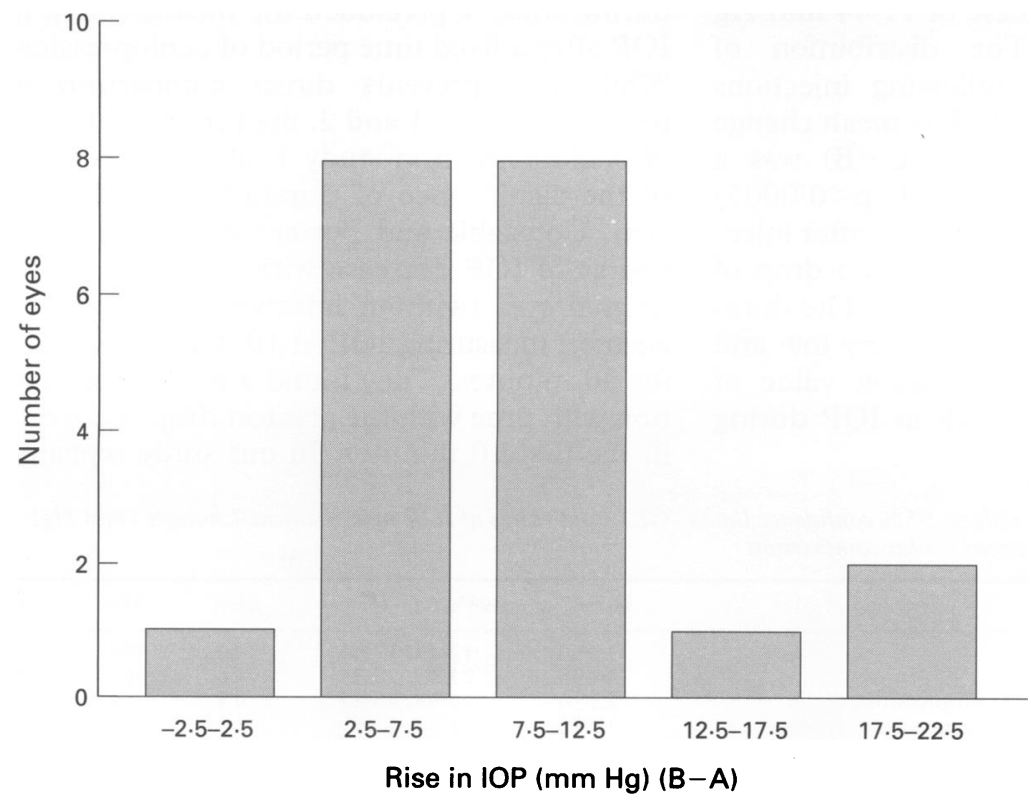

Figure 2 Study group 2: distribution of immediate rise in IOP after peribulbar injections oculopression was $26 \cdot 3$ minutes and most cases were well above the possibly critical 10 minute period. Further studies using a range of lower values of duration of oculopression might reveal a positive correlation between effect and duration below a certain critical value.

Having noted the variability in and the occasional large value of the initial pressure rise, it is reassuring to observe that a large injection induced rise in IOP is followed by a large fall. Although the highest injection induced IOP rise was $31 \mathrm{~mm} \mathrm{Hg}$ the highest net rise in IOP after injection and oculopression was $7 \mathrm{~mm} \mathrm{Hg}$. The mean net change was in fact a fall of $2.4 \mathrm{~mm} \mathrm{Hg}$.

Concern has been expressed about possible temporary large rises in IOP when the balloon is first applied and indeed such rises have been demonstrated in fresh cadavers by $\mathrm{McD}$ Donnell et $a l^{8}$ who found that larger rises occurred if the IOP was already high at time of application of the balloon. In view of this concern, is oculopression actually necessary?

The results from study group 2 show that there is a tendency for the IOP to fall after the peribulbar injection even without oculopression but that this tendency is greatly enhanced by oculopression. The mean fall in IOP during the second 20 minutes (with oculopression) of $11.55 \mathrm{~mm} \mathrm{Hg}$ was much larger than the mean IOP drop during the first 20 minutes (without oculopression) of $2.85 \mathrm{~mm} \mathrm{Hg}(p<0.0005)$. After 20 minutes without oculopression, the mean IOP was therefore still $6.6 \mathrm{~mm} \mathrm{Hg}$ higher than its original value. If time were to account for any difference between the first and second 20 minutes the greater drop would be expected in the first 20 minutes. ${ }^{35}$ The difference must therefore be accounted for by the presence of the oculopression and this study confirms its importance in preoperative IOP reduction.

We have, therefore, demonstrated that ocular compression with a Honan balloon is highly effective in lowering IOP after peribulbar injections. Our results contradict those of Morgan and Chandna who found that the rate of fall in IOP was comparable either with or without compression with the Honan balloon. ${ }^{7}$ They used a lower volume of injection $(8 \mathrm{ml})$ and although the technique used was uniform between the two authors, each used a different

Table 3 Summary of findings

(1) There is a variable and sometimes very large increase in IOP associated with administration of peribulbar anaesthesia even when the same agents are administered in the same volumes by the same surgeon. Mean values of $11.44 \mathrm{~mm} \mathrm{Hg}$ (study 1) and $9.45 \mathrm{~mm} \mathrm{Hg}$ (study 2)were found using $10 \mathrm{ml}$ of anaesthetic agents.

(2) There is a natural tendency for the IOP to fall in the period following peribulbar injection without oculopression but this produced a drop in IOP of less than a third of the value of the induced pressure rise during the first 20 minutes and the mean IOP at this stage was $6.6 \mathrm{~mm} \mathrm{Hg}$ higher than original.

(3) This tendency is greatly enhanced by oculopression, an effective measure producing a drop in IOP such that the mean overall change in IOP as a result of injections and

oculopression was a drop of $2.4 \mathrm{~mm} \mathrm{Hg}$.

(4) Duration of oculopression in the range of values used in study 1 (7-60 minutes) was not found to be a significant factor influencing IOP drop by linear regression analysis. 
combination of anaesthetic agent. The group receiving no oculopression had IOP values measured at 1 minute intervals using the Tonopen. They found that by 4 minutes postinjection (without oculopression), IOP values no longer differed significantly from their preinjection levels. After that time, there was little change in IOP in any given patient which would suggest that repeated measurement with the Tonopen did not lower IOP. It was still possible, however, that the Tonopen was effective in lowering IOP during the first 4 minutes, when the IOP values were higher. We were surprised by Morgan and Chandna's results and we await further studies by other groups to clarify the situation. A further single surgeon, single technique study with measurement of IOP values at a fixed time of 5 to 10 minutes is recommended. Based on our results and those of others, ${ }^{4-6}$ we would recommend the use of the Honan balloon after peribulbar anaesthesia.
We thank Mr Declan Flanagan, FRCOphth, for allowing access to patients under his care and Dr T Aitchison for statistical advice.

1 Meyer D, Hamilton RC, Loken RG, Gimbel HV. Effect of combined peribulbar and retrobulbar injection of large volumes of anaesthetic agents on the intraocular pressure. Can f Ophthalmol 1992; 27: 230-2.

2 Stevens J, Giubilei M, Lanigan L, Hykin P. Sub-Tenon, retrobulbar and peribulbar local anaesthesia: the effect upon intraocular pressure. Eur f Implant Ref Surg 1993; 5: 25-8.

3 O'Donoghue E, Batterbury M, Lavy T. Effect on intraocular pressure of local anaesthesia in eyes undergoing intraocular surgery. Br $\mathcal{F}$ Ophthalmol 1994; 78: 605-7.

4 Zahwa A, Assouline M, Goldstein A, Legras JM, Renard G, Pouliquen Y. Peribulbar anaesthesia: the effect of high injection volumes and orbital compression on intraocular pressure. Invest Ophthalmol Vis Sci 1995; 36: S809.

5 Constable PH, Porter EJB. Extraocular compression prior to cataract surgery: time course of reduction and subsequent recovery of intraocular pressure. Eye 1993; 7: 731-4.

6 Ropo A, Ruusuvaara P, Paloheimo M, Maunuksela E-L, Nikki P. Effect of ocular compression (Autopressor) on intraocular pressure in periocular anaesthesia. Arch intraocular pressure in perio
Ophthalmol 1990; 68: 227-9.

7 Morgan JE, Chandna A. Intraocular pressure after peribulbar anaesthesia: is the Honan balloon necessary? $B r f$ Ophthalmol 1995; 79: 46-9.

8 McDonnell PJ, Quigley HA, Maumenee E, Stark WJ, Hutchins GM. The Honan intraocular pressure reducer. Arch Ophthalmol 1985; 103: 422-5. 